\title{
Short term functional training improves completion quality of body difficulty of juvenile rhythmic gymnasts
}

\author{
Formação funcional a curto prazo melhora a qualidade de conclusão da dificuldade do \\ Corpo dos ginastas rítmicos juvenis \\ Breve término mejora funcional de la calidad de la finalización de las dificultades físicas de \\ juvenile rhythmic gymnasts
}

Yu-ke Qin ${ }^{\mathrm{a}, \mathrm{b}}(\mathbb{D})$, Jie Zeng ${ }^{\mathrm{a}}$ (D) , Li Penga* (1)

Keywords:

Functional training;

Body difficulty;

Completion quality;

Rhythmic gymnasts.

Palavras-chave:

Formação funcional;

Dificuldade física;

Qualidade de

conclusão;

Ginásios rítmicos.

Palabras clave:

Formación funcional; Dificultades físicas;

Calidad de la obra;

Gimnastas de arte.

\begin{abstract}
To explore the impact of functional training on completion quality of body difficulty, 24 rhythmic gymnasts aged 10-11 years old were randomly and averagely divided into functional training and control group and trained $2 \mathrm{~h}$ /day for 1 month. Body difficulty - including balance, rotation, and leap difficulties - was measured before and after training. The results showed that the total score, the score of $360^{\circ}$ passé pivot and the score of split leap for the functional training group was respectively $1.87,0.77$, and 0.42 points higher than those for the control group $(P<0.05)$ after 1 month of training. Therefore, it can be concluded that functional training based on Functional Movement Screen (FMS) can clearly improve completion quality of body difficulty in juvenile rhythmic gymnastics within a short period of time.
\end{abstract}

\section{RESUMO \\ Para explorar o Impacto Da formação funcional Na qualidade de conclusão Da dificuldade do corpo, OS ginastas rítmicos 24.o com Dez Anos de idade 10-11 foram aleatoriamente divididos EM Grupo de formação funcional Ou Grupo de controlo e EM formação contínua $2 \mathrm{~h} /$ dia para um mês.A dificuldade do corpo, incluindo dificuldades de equilíbrio, dificuldades de rotação, dificuldades de Salto foram medidas antes e depois Da formação.Os resultados mostraram pontuação total, pontuação Da rotação de Passos de $360^{\circ}$ e Salto Split no Grupo de treinamento funcional FOI respectivamente 1.87, 0.77 e 0.42 Pontos Mais elevados do que aqueles no Grupo de controle (todos $\mathrm{P}<0.05$ ) após o treinamento de um mês. Por conseguinte, Pode concluir-se que a formação funcional baseada no SGF Pode obviamente melhorar a qualidade de conclusão Da dificuldade corporal Da ginástica rítmica juvenil num curto período de tempo.}

\section{RESUMEN}

Los resultados mostraron que el grupo de control y el grupo de gimnasia rítmica de 10 a 11 años de edad fueron de dos horas de entrenamiento al día durante un mes. Las dificultades físicas, incluidas las dificultades de equilibrio, rotación y salto, se miden antes y después del entrenamiento. Los resultados mostraron que la puntuación total, la puntuación de $360^{\circ}$ passe pivot y la puntuación de split-jump fueron respectivamente $1,87,0,77$ y 0,42 mayores en el grupo de entrenamiento funcional que en el grupo control después de 1 mes de entrenamiento $(P<0,05)$. Los resultados muestran que el entrenamiento funcional basado en la detección de movimiento funcional (FMS) puede mejorar significativamente la calidad de la realización de las dificultades físicas en la gimnasia rítmica de los adolescentes en un corto período de tiempo.

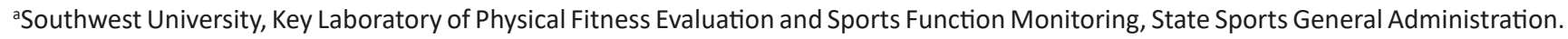
Chongqing, China.

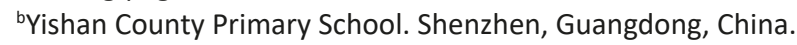

\author{
*Corresponding author: \\ Li Peng \\ E-mail: 804455169@qq.com
}




\section{INTRODUCTION}

International rhythmic gymnastics is developing in the direction of new, skillful, fine, stable, and artistic performance. The difficulty score of the new cycle rules from 2017 to 2020 mainly consists of four categories: body difficulty, dance step combination, dynamic elements with rotation, and apparatus difficulty. The changes in the new rules concerning technical characteristics are mainly as follows: body difficulties increase technical apparatus difficulties on the basis of balances, rotations, and leaps. The new rules require individual juvenile athletes to have no less than one body difficulty of each type in the complete set of movements, and the correct and successful completion of the seven highest body difficulty movements in the complete set will be included in the score. They are more stringent regarding body posture when completing difficult movements, such that a difference from $10^{\circ}$ to $20^{\circ}$ degrees results in a loss of 0.1 to 0.3 points and body difficulty is invalidated with a loss of 0.5 points if the difference is above $20^{\circ}$. In view of this, the new cycle rules undoubtedly put forward higher standards for rhythmic gymnasts to complete the movements of body difficulty; therefore, it is necessary to explore efficient and targeted training methods.

Functional training was proposed in the 1990s by Gray Cook, an American orthopedic specialist, and Mike Boyle, a physical training specialist. Cook G (Cook, 2003). designed a screening system based on action mode to predict motor risk - the "Functional Movement Screen (FMS)" consisted of squatting, stepping, lunging, reaching, leg raising, rotary stability and push-up. The stability and flexibility of each joint were tested to evaluate obvious functional skeletal asymmetry and posture defects. Integral functional training improves muscle strength, balance, coordination, and explosive power through coordination of body muscles (Qi, 2011). Verstegen M (Verstegen and Williams, 2005, 2006) proposed that "the essence of sports is a movement." ACSM guidelinses (Pescatello et al., 2014) believes that all functional training forms include acceleration, stabilization, and deceleration in the three-dimensional plane of the kinetic chain in sports. Gambetta V (Gambetta and Gary, 1995; Gambetta, 2004) believed functional training has more forms than general physical training. Then, functional training is a method involving action training aimed at improving muscle coordination, joint stability, and body control. Researchers found that training for stability in the core area of rhythmic gymnastics has a positive effect on the quality of athletes' turning movements (Qing, 2013). The application of functional training to delicate and artistic sports such as rhythmic gymnastics is helpful to further develop the practical application of functional training and may also promote improvement of competition performance in such sports. Therefore, based on FMS for juvenile rhythmic gymnasts, a 1-month functional training program was designed in this study, where its effect on completion quality of body difficulty of rhythmic gymnasts was observed. The main purpose of this research is to explore efficient and targeted training methods for juvenile rhythmic gymnasts by observing the influence of functional training on completion quality of body difficulty.

\section{METHODS}

\section{SUBJECTS}

All of the study's subjects belong to the same rhythmic gymnastics team. The inclusion criteria were: being third-class rhythmic gymnastics players; being 10-11 years old; having more than 3 years of training history; not presenting physical pain. The 24 participants included and their guardians received detailed information sheets, were informed, and signed informed consents, as required by ethical standards. The study was approved by the Human Research Ethics Committee of Southwest University (SWU-TY201809). The subjects were randomly averagely divided into experimental group and control group by means of an automated random number generation method. The age, height, weight, and training history difference (Table 1) between two groups was not significant $(P<0.05)$.

\section{TRAINING}

A functional training program was designed for the experimental group to improve the stability of lower limbs and core areas, supplemented by fast strength and endurance exercises (Table 2), according to the results of the FMS test. In both groups, training was conducted under guidance of professional rhythmic gymnastics coaches at different venues at the same time for 2 hours a day and lasted for 30 days. During training, assistant coaches recorded the sessions in video from the side of the training area for the researchers to control the overall training load according to subjective evaluations and the subjects' objective performance.

\section{FMS TEST AND EVALUATION}

The FMS was evaluated by the same researcher and was scored according to four levels: 0 point - when pain is felt at any part of test; 1 point - when the action is not

Table 1. Basic information of the subjects in the experimental and control group $\left({ }^{-} X \pm S D\right)$.

\begin{tabular}{lcccc}
\hline \multicolumn{1}{c}{ Group } & Height $(\mathbf{c m})$ & Weight(kg) & Age(years) & Training time(years) \\
\hline Experimental group $(n=12)$ & $139.29 \pm 3.19$ & $28.9 \pm 2.28$ & $10.17 \pm 0.39$ & $3.42 \pm 0.51$ \\
Control group $(n=12)$ & $138.07 \pm 3.34$ & $27.96 \pm 2.58$ & $10.33 \pm 0.49$ & $3.42 \pm 0.51$ \\
\hline
\end{tabular}


Table 2. Training plans for the control and experimental group.

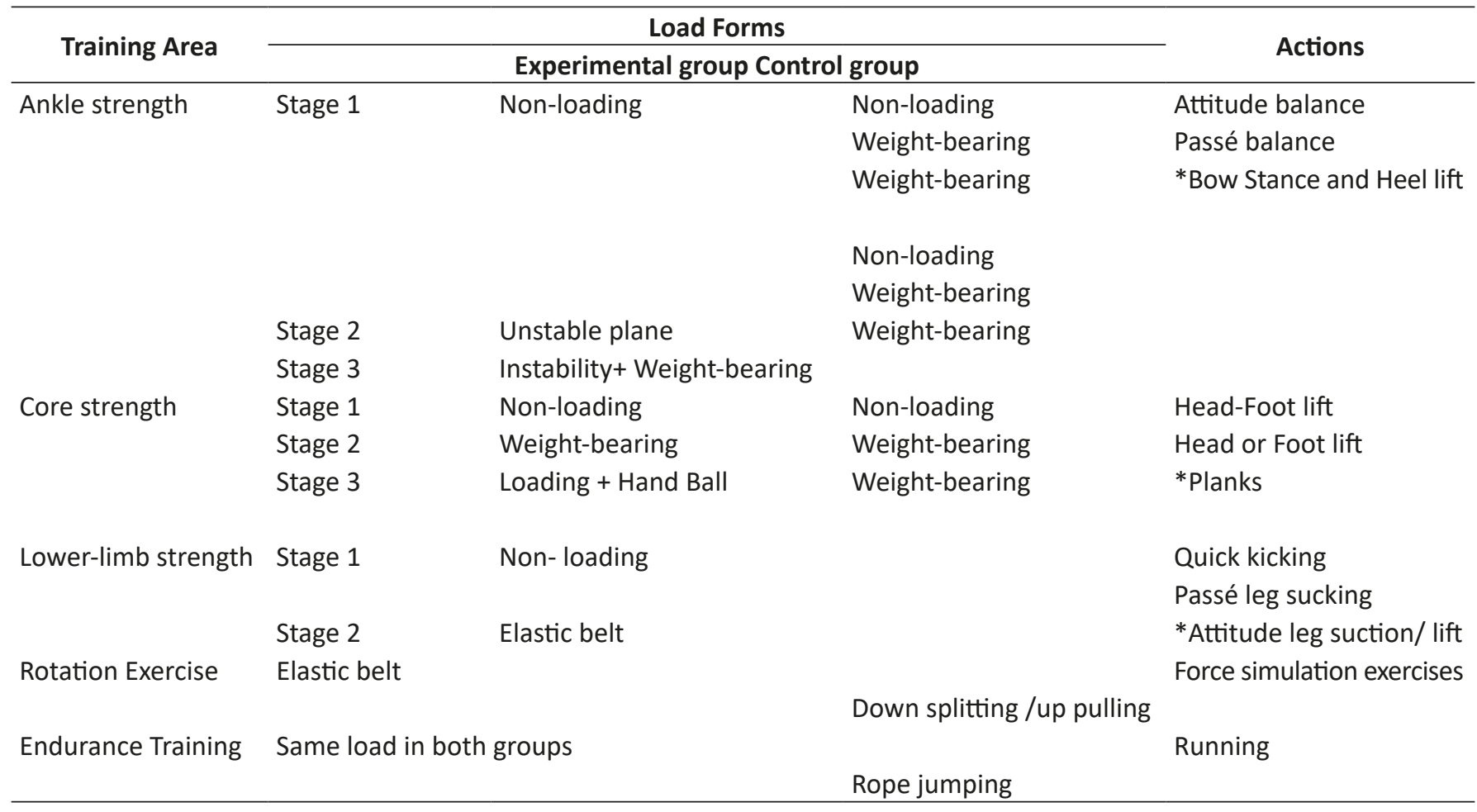

*Specific training action in the experimental group. Duration of each stage: Stage 1: Days 1-10; Stage 2: Days 11-20; Stage 3: Days 21-30

completed in its entirety or when the starting posture is not maintained; 2 points - when the entire action is completed with low quality; 3 points - when the entire action is completed with high quality.

\section{MEASUREMENT AND EVALUATION OF BODY DIFFICULTY}

Measurement and evaluation of body difficulty including many postures, actions, and links of balance (passé balance, attitude balance), rotation ( $360^{\circ}$ passé pivot, $360^{\circ}$ attitude pivot), and leap (split leap, stag leap) - were conducted by two national rhythmic gymnastics judges according to the international rules of rhythmic gymnastics. The final score is the average of all items scored.

\section{MATHEMATICAL STATISTICS}

All data were processed and analyzed by the software SPSS21.0. An independent sample T-test and a paired sample T-test were used for the difference between groups and intra-group comparisons before and after training, respectively. The tests were two-sided with a Type I error set at $\alpha=0.05 .3$.

\section{RESULTS}

\section{FMS RESULTS BEFORE TRAINING}

As shown in Table 3, except for achieving shoulder flexibility, the rhythmic gymnastics in this study did not obtain high scores in squatting, stepping, lunging, rotary stability, and push-up. The poor scores in these items indicated problems with stability and flexibility of trunk and hip, knee and ankle, and poor coordination in various parts. However, there was no significant difference in the FMS scores between groups before training $(P>0.05)$.

\section{EFFECT OF FUNCTIONAL TRAINING ON COMPLETION QUALITY OF BODY DIFFI- CULTY}

As shown in Table 4, no significant difference was found between groups in total score, rotations, balances, and leaps before training $(P>0.05)$. After 1 month of training: the total score of body difficulty, $360^{\circ}$ passé pivot and split leap in the experimental group was respectively $1.87,0.77$, and 0.43 points higher than those in the control group $(P<0.01)$. In the experimental group, total score, $360^{\circ}$ attitude pivot and attitude balance were respectively $2.95,0.89$, and 0.65 points higher than those before training $(P<0.01)$. The split leaps and stag leaps were significantly improved -0.77 and 0.36 points $(P<0.01)$ higher than those before training, respectively. In the control group, the total score also improved significantly 1.51 points higher than that before training $(P<0.01)$. The $360^{\circ}$ attitude pivots, split leaps, and stag leaps improved by $0.79,0.14$ and 0.12 points respectively $(P<0.05)$. 
Table 3. Comparisons of the FMS scores of juvenile rhythmic gymnasts between the experimental and the control group before training $\left({ }^{-} X \pm S D\right)$.

\begin{tabular}{lcccc}
\hline \multicolumn{1}{c}{ FMS } & Experimental group & Control group & T-Value & P-Value \\
\hline Squatting & $2.00 \pm 0.00$ & $2.00 \pm 0.00$ & - & - \\
Stepping & $2.00 \pm 0.00$ & $2.00 \pm 0.00$ & - & - \\
Reaching & $3.00 \pm 0.00$ & $3.00 \pm 0.00$ & - & - \\
Lunging & $2.17 \pm 0.57$ & $2.25 \pm 0.45$ & -0.36 & 0.72 \\
Leg Raising & $2.17 \pm 0.84$ & $2.17 \pm 0.39$ & 0.00 & 1.00 \\
Rotary Stability & $2.00 \pm 0.00$ & $2.00 \pm 0.00$ & - & - \\
Push-up & $2.08 \pm 0.29$ & $2.08 \pm 0.29$ & - & - \\
FMS total score & $15.42 \pm 0.79$ & $15.58 \pm 0.79$ & -0.69 & 0.50 \\
\hline
\end{tabular}

Table 4. Comparisons of the body difficulty scores of juvenile rhythmic gymnastics between the experimental and the control group before and after training $\left({ }^{-} X \pm S D\right)$.



\section{DISCUSSION}

Shoulder and neck, trunk and hip, knee and ankle are the three main supporting structures of the body as a closed chain when standing. The movement signals are transmitted between shoulder and neck, trunk and hip, knee and ankle. FMS can uncover insufficient body flexibility and stability - for example, squatting can evaluate bilateral balance and functional flexibility of the hip, knee and ankle joints at the same time, while the rotational stability test can evaluate the trunk stability in multiple dimensions when upper and lower limbs move simultaneously. The overall reliability of FMS raters is good (Hua et al., 2016). The FMS screening in this study shows that juvenile rhythmic gymnasts presented some problems with the balance of trunk and hip, knee and 
ankle stability and flexibility. Chunlei (2015) evaluated the functional movements of 10 members in the Chinese national rhythmic gymnastics team and found asymmetrical muscles between left and right side; in addition, the total score of FMS was low, reaching under 14 points. Chunlei (2018) believes that changes in the length of muscles and soft tissues can affect control of movement, resulting in erroneous postural force lines and movement patterns.

In view of the above and according to the FMS results and following the characteristics of functional training "multi-dimensional and multi-joint", "kinetic chain", and " human core area" (Zhou, 2016), using Yan Qi's physical training pyramid model as reference to determine the exercise load (Qi, 2012) combining growth and development rules of children aged 10-11 years old (Wang and Su, 2011), this study designed a functional training program with waist, abdomen, and lower limbs as main training areas and prioritizing core stability strength (erector spine muscle, rectus abdominis muscle, iliopsoas muscle) and fast strength training of lower limbs (gastrocnemius muscle and soleus muscle), supplemented by flexibility and low-intensity aerobic endurance (running of $1,500 \mathrm{~m}$, rope jumping). The core stability strength exercise is designed to address the problem of insufficient trunk stability and ankle strength link specifically for the flexibility and stability of ankle joint, and the lower limb strength link for the stability of hip and knee joint. The fast strength exercise of the lower limb is combined with a balance and flexibility exercise to address flexibility and coordination problems. With a two-hour daily training session, the overall exercise load is relatively low for professional training.

In terms of strength, rhythmic gymnastics pays more attention to the relative strength of athletes as they need to overcome their own gravity when completing basic technical movements such as balance, rotations, and leaps. Considering the long muscle length, weak contraction ability, and poor aerobic endurance of children aged 10-11 years, dynamic exercises are the main methods for lower limb strength training in this study, such as load plus elastic band kicking, load plus elastic band passé lifting, and a few static exercises. Although the rhythmic gymnasts' playing time is less than 2 minutes and 30 seconds, and glycolysis is their main feature for energy supply (Weidong, 1997), considering the law of growth and development, aerobic endurance training is more suitable for girls aged 8-12 years (Wang and Su, 2011). Therefore, in this study, aerobic endurance training is the main method of training, combined with a few anaerobic endurance exercises.

In view of the muscle development rule "trunk muscle first, limb muscle after", the core strength training was mainly combined with static and dynamic exercises, such as plank-support static exercises, plus alternating plank support with one-foot dynamic exercises, weightbearing supine foot-head-up, weight-bearing prone foot-head-up. Rhythmic gymnastics requires not only flexibility of joints in many ways, but also great control of the stretching muscles around them. Gray Cook emphasized that the primary requirement for joint training is joint flexibility and stability (Cook, 2003). Improving the nerve's ability to recruit muscle fibers can get the most of the athletes' flexibility and improve the speed of movement. Improving flexibility also promotes the improvement of strength and action speed (Zhang, 2012). The clear increase of athletes' fast strength can be reflected in the improvement of their nerve mobilization ability and coordination between active and antagonistic muscles. Therefore, the scheme was designed to improve flexibility and coordination by combining fast strength, flexibility, and balance exercises.

As the training objectives of the two groups in this study are identical, total completion quality of body difficulty in both groups has clearly increased after training. However, the total score of body difficulty and the score in the 360 o passé pivot and split leap of the experimental group was significantly higher than that of the control group. The functional training program focuses on improving athletes' weak chains, i.e. coordination and stability of posterior surface line mainly composed of vertical spine-sacral tubercle ligamentpopliteal muscle-gastrocnemius-plantar fascia and flexor digitorum brevis (Chunlei, 2018), which effectively addressed the problems of insufficient stability, poor flexibility, and coordination of the athletes' trunk and lower limbs in the short term.

Rotation is the most difficult and complex technique in rhythmic gymnastics because it not only shows balance ability, but also the muscle control ability. The 360 o passé pivot involves pedaling on the ground with a supporting leg as its axis, while the other side and leg swings into a passé posture by swinging up the leg. The two hands swing to three positions, tightening the core and raising the heel in the process of accelerating the swing until the action is completed. The degree of rotation is determined by the angular velocity of the trunk, where angular velocity is determined by swing leg, angular velocity of the arm, and speed of pedal and heel lifting of the supporting leg. Therefore, in order to improve the quality of rotation, the swing speed of arms and legs, the pedal and extension speed of the supporting leg, and the speed of heel lifting should be improved on the basis of core stability.

Arm swings requires the use of the glenohumeral joint and its surrounding muscles, including deltoid, circular, and latissimus dorsi (Haas, 2017). In designing this training program, core stability exercises were placed at the core, as well as dynamic rotary exercises for arm swing and an elastic band exercise for nervemuscle recruiting and muscle memory. Leg swings requires the use of the hip joint and its surrounding muscles (gluteus medius, tensor fasciae latae). In this study's training program, fast kicking, anterior suction control of passé, and small upward leg lifting of passé can accurately improve the quality of passé leg swing by 
training the contraction strength and speed of tensor fasciae Latae and gluteus medius muscles. The ankle joint (deltoid ligament, plantar calcaneal ligament, anterior talofibular ligament, calcaneoclavicular ligament, posterior talofibular ligament) and its surrounding muscles (gastrocnemius muscle, soleus muscle) were used for both rapid pedaling and fast heel elevation. In addition, knee joint and its surrounding muscles (anterior tibial muscle, quadriceps femoris) were also used for rapid pedaling, and the ankle strength link, for ankle joint flexibility and stability, while lower limb strength link was used for the stability of knee joint.

Jumping is one of the basic technical movements in rhythmic gymnastics. A high-quality leap requires both good jumping strength and high technical level. Split leap requires athletes to overcome their own gravity, to push their left foot forward and take off, and swing the right leg forward and upward with the tightening legs' muscles, and stretch both thighs to the maximum very fast. Then, the right foot is cushioned, and the left immediately follows.The four technical stages of kneebending squatting, kicking and stretching, flying and landing are the main components of the split leap, the key of which is height and flight time, so it is very important to increase jump height and flight time while ensuring the opening of the free leg in the training session. According to a principle of biomechanics, the higher the initial speed of take-off, the higher the jump height and the longer the time of take-off (Committee of National Institute of Physical Education, 2008). Thus, overcoming gravity in quick take-off becomes the key factor to improve split leap quality.

Quick take-off is a series of actions that requires continuity and coordination. A quick run-up is followed by knee bending, squatting, and then kicking, stretching and taking off. In fast take-off, athletes mainly use the quadriceps femoris, hamstrings, gastrocnemius, and soleus muscles; in the flight of thighs, they mainly use rectus abdominis, iliopsoas, quadriceps femoris, erector spine, gluteus maximus, and hamstring muscles; in order to achieve a light and feathery sense of gravity when landing on one foot, they need to tighten the core while hovering in the air and while the hamstring muscles are contracted. The legs are extended forward and upward consciously, followed by a fall and knee flexion to cushion. In this study, training lower limbs such as with weightbearing kicking and kicking with load and elastic belt on the ground was designed to improve fast contraction of the iliopsoas, gluteus maximus, and hamstring muscles, while ankle strength training such as heel lifting and vertical jumping enhanced stability of ankle at the same time. The elasticity of ligaments around ankle joints such as deltoid ligament, plantar calcaneal ligament, and posterior talofibular ligament is enhanced to improve jumping ability and fast kick- and take-off.

The total score of the juvenile rhythmic gymnasts in the experimental group is clearly higher than that of control group, which demonstrates the efficacy of this study's training design. However, the functional training program in this study neglects the comparison of flexibility, stability, and dynamic balance between the two sides of the body, for example, exercises to improve symmetrical balance were not fully considered as leading to the failure in the balances score of young rhythmic gymnasts.

\section{CONCLUSIONS}

The functional training program designed in this study can clearly improve the completion quality of body difficulty in juvenile rhythmic gymnasts within a short period of time, which was mainly reflected in the remarkable improvement of the scores of leap and rotation, showing that FMS results based on the balance of physical stability and flexibility are helpful to design training programs.

\section{FUNDING}

This work was supported by Southwest University Innovation Team Research Project (SWU1909105).

\section{CONFLICTS OF INTEREST}

All authors declare that there is no conflict of interest.The authors alone are responsible for the content and writing of the manuscript.

\section{REFERENCES}

Chunlei L. Analysis of the screening result of Athletes' Functional Movements of China National Rhythmic Gymnastics team and corrective training. Sports Sci Res. 2018;4:94-101.

Chunlei L. The present situation of functional movement quality of Chinese national rhythmic gymnastics team and its corrective and improving measures. Movement. 2015(1):105.

Committee of National Institute of Physical Education. General textbook of Physical Education College specializing in rhythmic gymnastics. Beijing: People's Sports Publishing House; 2008.

Cook G. Athletic body in balance. Champaign: Human Kineties Publishers; 2003.

Gambetta V, Gary G. Athletic development. Champaign: Human Kineties Publishers; 2004.

Gambetta V. Following a functional path. Train Cond. 1995;5(2):25-30

Haas JG. Dance anatomy. Translated by Wang Huiru. Zhengzhou Henan: SCI TECHNOL PUBL House; 2017.

Hua W, Hui R, Zhang X. An empirical study on interrater reliability in functional motion screening. J of Chengdu Sport University, 2016;6(42):99-102.

Pescatello LS, Riebe D, Thompson PD, editors. ACSM's guidelines for exercise testing and prescription. Filadélfia, Pensilvânia, EUA: Lippincott Williams \& Wilkins; 2014.

Qi Y. Construction and empirical study of functional physical training method system for elite women hockey players. Hebei, China: Hebei Normal University; 2012. 
Qi Y. Development of functional physical training in China. J of Beijing Sport University. 2011(4):34-6.

Qing H. Study on the effect of stability training in core area on the quality of difficulty of rhythmic gymnasts in completing their physical exercises. Beijing: Beijing Sports University; 2013.

Verstegen M, Williams P. Core performance essentials. St. Martins Pr.; 2006. p. 5-20.

Verstegen M, Williams P. Core performance. Emmaus, Pensilvânia: Rodale Books; 2005. p. 2-10.
Wang R, Su Q. Sports physiology. Beijing: People's Sports Publishing House; 2011.

Weidong L. Discussion on the main characteristics of modern rhythmic gymnastics training. J of Wuhan Sports $U$. 1997(3):54-6.

Zhang Y. Frontier practice of functional movement training in competitive sports. Shandong Sports SCI TECHNOL. 2012;34(2): 4.

Zhou Z. An empirical study on functional training promoting gross motion development of children aged 5-6 yrs. J of Chengdu Sports U. 2016;042(005):16-22. 